\title{
0 caso do registro da viola-de-cocho como patrimônio imaterial
}

\author{
Letícia Vianna*
}

\begin{abstract}
R esumo: A viola-de-cocho é um instrumento musical singular, típico de localidades de Mato Grosso e Mato Grosso do Sul. Este texto trata de questões relacionadas ao registro desse instrumento como patrimônio imaterial no Livro dos Saberes do Instituto do Patrimônio Histórico e Artístico Nacional (Iphan).
\end{abstract}

Palavr as-chave: altura pqular; patrimânio imaterial; registro; políticas de salvaguarda.

A viola-de-cocho é um instrumento musical singular e especial em relação à forma e à sonoridade. Encontrada em M ato Grosso e $M$ ato Grosso do Sul, costuma acompanhar-se de ganzá e tamborim ou mocho. Integra o complexo musical, coreográfico e poético do cururu e do siriri, cultivado por segmentos das camadas populares como diversão ou devoção a santos católicos.

Conforme evidências etnográficas, a região do alto Rio Cuiabá pode ser definida como um importante núcleo de difusão desse complexo cultural. Depois da divisão do estado de $M$ ato Grosso, em 1978, surgiu o novo estado de $M$ ato Grosso do Sul e, naturalmente, as tradições culturais do cururu e siriri e da viola-de-cocho mantiveram a contigüidade espacial nos dois estados.

A viola-de-cocho foi reconhecida como patrimônio nacional, registrada no Livro dos Saberes do patrimônio imaterial brasileiro em dezembro de 2004. Foi o quinto bem de natureza imaterial a ser registrado pelo Instituto do Patrimônio Histórico e A rtístico Nacional (I phan).

0 registro nos livros do patrimônio imaterial do Iphan é um instrumento institucional de

\footnotetext{
* Mestre em Antropologia pelo PPGAS/UnB, doutora em A ntropologia pelo PPGAS/M useu Nacional/URFJ e professora, autora de livro e artigos sobre cultura popular. E-mail: viannaleticia@ig.com.br
}

salvaguarda relativamente novo. E não se confunde com registro documental (etnográfico, fonográfico, fotográfico, filmográfico, jornalístico). Embora a documentação faça parte desse registro - que também não se confunde com 0 registro cartorial (de marca, patente, origem, propriedade) ou de qualquer outra natureza. 0 registro, do qual se trata, significa o reconhecimento oficial por parte do Estado brasileiro do valor cultural de uma determinada expressão humana para a construção da identidade nacional.

Este texto foi produzido com a imensa colaboração de Elizabeth Travassos L ins e de E dilberto Fonseca e traz, de maneira sintética, al gumas questões relativas ao processo de pesquisa, inventário, registro no livro do I phan, e da salvaguarda por meio deste da viola-de-cocho - processo desenvolvido pelo Centro $\mathrm{N}$ acional de Folclore e Cultura Popular (CNFCP), no bojo de projeto de valorização da riqueza, pluralidade, diversidade e criatividade cultural como fator de unidade nacional.

Celebrações e saber es: o contexto institucional e metodológico do processo desse registro

A té o momento, podemos dizer que, no B rasil, existem vários instrumentos de proteção 
e salvaguarda do patrimônio cultural. Dentre os quais podemos destacar o tombamento, a pesquisa, a documentação e os inventários, 0 fomento à reprodução de saberes e técnicas e a difusão pelos mais variados meios e mídias.

Como se sabe, o registro do patrimônio imaterial é instrumento relativamente recente no rol de instrumentos de salvaguarda já desenvolvido e foi criado com base em estudos e discussões no sentido de aperfeiçoar a legislação brasileira já existente na área do patrimônio cultural. Está voltado para os bens cujo valor patrimonial transcende suas expressões ou realizações materiais. Protege, sobretudo, os saberes, as motivações, os sentidos e as condições de produção, a criatividade e a dinâmica cultural por meio de planos de salvaguarda pontuais.

Foi instituído pelo Decreto 3551, de agosto de 2000, que cria os L ivros dos Saberes, Formas de Expressão, Lugares e Celebrações. E cria também o Programa Nacional do Patrimônio Imaterial, direcionado para o fomento de políticas de proteção e salvaguarda desse tipo depatrimônio.

A viola-de-cocho foi registrada no Livro dos Saberes. Toda a documentação que compôs 0 dossiê de registro enfatizou tanto os saberes associados ao modo artesanal de produção quanto as formas de expressão associadas: 0 cururu e o siriri.

0 dossiê de registro foi elaborado por uma equipe de técnicos do Centro $\mathrm{Nacional}$ de Folclore e Cultura Popular (CNFCP), como um dos vários resultados do Projeto Celebrações e Saberes da Cultura Popular, desenvolvido, desde o final de 2000, no âmbito do Programa N acional do Patrimônio Imaterial.

Esse projeto foi estruturado em linhas de pesquisas, temas e subprojetos articulados em diferentes lugares do país, estabelecendo interlocução com diferentes segmentos sociais, no sentido de desenvolver ações que contribuíssem para o estabelecimento de políticas pontuais de salvaguarda do patrimônio das culturas populares. Desde o início, contou com recursos do M inistério da Cultura e várias parcerias e apoios em projetos integrados, destacando-se a parceria com a Petrobras em alguns projetos e o apoio técnico da Faperj.
Foi uma espécie de piloto, no sentido de criar experiências e testar a aplicabilidade e os limites do registro e do Inventário Nacional de Referências Culturais (INRC). O INRC foi desenvolvido pelo I phan como uma metodologia de inventário para ser aplicada no levantamento do patrimônio imaterial e compõe o rol de inventários dessa insti tuição, que já dispunha de algumas metodologias de inventário, como as voltadas para o bens móveis, bens imóveis esítios urbanos e arqueológicos.

A experiência do Projeto Celebrações e Saberes da Cultura Popular foi, assim, organizada a partir da combinação desses instrumentos de salvaguarda implementados em 2000 pelo I phan (Inventário Nacional de Referências Culturais (INRC) e registro nos Livros do Patrimônio (material), com modos e instrumentos já conhecidos e eficazes (repasse de saberes, valorização, pesquisa e documentação, apoio e difusão por diferentes meios e mídias), que já integravam linhas de ação do CNFCP, como exposições, publicações, projetos de apoio e fomento à produção e à reprodução.

A o longo de todas as etapas do projeto, foi desenvolvida uma reflexão permanente sobre as fronteiras que circunscrevem os bens patrimonializáveis, os inventários culturais, suas implicações metodológicas e éticas. E suas funções como instrumento de salvaguarda. Debate que se materializou em publicações sistemáticas.

As linhas de pesquisa foram traçadas de modo a equacionar pluralidade cultural eunidade nacional. 0 ponto de partida foram elementos culturais que fossem comuns, mas que assumissem especificidades em sistemas culturais diferentes, tais como os complexos culturais em que os elementos boi, barro, feijão, mandioca, viola e percussão se destacam como referência cultural. A s linhas não teceram camisas-deforça e foram bastante elásticas, de modo que, no último ano, outros temas entraram na trama, por tessituras oblíquas. Na primeira etapa do projeto foram abertos vários inventários: cerâmica de Candeal (MG) e Rio Real (BA); Bumba-meu-boi (M A); acarajé (BA) farinha de mandioca (inicial mente a partir do Pará); jongo (região Sudeste), e viola-de-cocho (M S e M T). $\mathrm{N}$ em todos derivaram em registros. 
$M$ as o interesse do CNFCP pelo universo cultural da viola-de-cocho é bem anterior ao Projeto Celebrações e Saberes da Cultura Popular. Faz duas décadas, pelo menos, que vem desenvolvendo ações de reconhecimento e valorização desse universo - ações integradas às linhas de trabalho da instituição. Em 1988, foi realizada a exposição Viola-de-cocho, na Sala do A rtista Popular, no CN FCP (RJ) ), a qual foi baseada em pesquisas etnográficas realizadas em $M$ ato Grosso. Os resultados dessas pesquisas foram editados em catálogo da exposição, que circul ou amplamente. Também foi editado, em 1988, o LP Cururu e outros cantos das festas religiosas - MT, com performances musicais colhidas em campo, pelos mesmos pesquisadores.

D esde então, o CNFCP tem acompanhado esse universo cultural com especial atenção aos acontecimentos mais marcantes, como a tentativa frustrada de registro da marca viola-decocho por um indivíduo e a intensa mobilização popular que se seguiu no $M$ ato Grosso, repudiando 0 ato. Esse fato serviu para os técnicos da instituição como mais um alerta geral sobre a gravidade de questões relativas à sal vaguarda do patrimônio cultural, de comunidades específicas e da nação como um todo. Trouxe subsídios para o amadurecimento da reflexão sobre a importância de instrumentos de salvaguarda de direitos e saberes oriundos das culturas populares.

A ssim, a viola-de-cocho foi, desde o início, um do temas abordados, pois acreditava-se ser este um caso exemplar, e interessantíssimo, para compor esse projeto piloto, por várias razões: a especificidade da viola-de-cocho como instrumento musical; os riscos de descaracterização; os riscos de desaparecimento; os riscos de desapropriação, dado o fato recente de ter sido objeto de registro de marca junto ao INPI registro que não se consolidou; o fato de ter sido tombada nos dois estados da federação onde são encontradas (mesmo não sendo o tombamento 0 instrumento mais apropriado do ponto de vista da nova legislação, ele reflete o reconhecimento oficial do val or patrimonial do bem cultural), e a importância de ampla divulgação nacional desse bem cultural tão especial e representativo da riqueza e da pluralidade culturais brasileiras.

0 inventário da viola-de-cocho foi, então, inicialmente aberto no Livro dos Ofícios e M odos de Fazer, inscrevendo-se a confecção do instrumento. $E$ teve continuidade no Livro das Formas de Expressão, destacando-se 0 cururu e o siriri - os complexos musicais e coreográficos que tradicionalmente envolvem essa viola em M ato Grosso e M ato Grosso do Sul.

Logo no início de 2001, o CNFCP recebeu uma espécie de "pedido de socorro" vindo de Corumbá e L adário (MS), chamando a atenção para o risco de desaparecimento dos conhecimentos sobre o modo de fazer a viola-de-cocho nessas localidades, tendo em vista a idade avançada dos poucos cururueiros que dominam 0 artesanato do instrumento. De modo que, na linha de trabalho de apoio às comunidades artesanais, foi implementado e realizado o Projeto Viola-de-cocho Pantaneira, em parceria com o Programa A rtesanato Solidário e com recursos da BR Distribuidora.

A ssim, ações de apoio e fomento foram sendo desenvolvidas concomitantemente às pesquisas para o Inventário de Referências Culturais (INRC) da viola-de-cocho. Essa articulação de projetos fez com que a aplicação do INRC não fosse desvinculada de ações de sal vaguarda desenvolvidas de maneira imediata em localidades específicas. E essas ações pontuais serviram como piloto para 0 desenvolvimento dos principais pontos lançados como sugestão do plano de salvaguarda, o qual acompanhou a instrução para o registro do instrumento como patrimônio nacional.

\section{A viola-de-cocho, o cururu e o siriri}

0 nome do instrumento deve-se à mesma técnica usada para a fabricação do cocho espécie de gamela escavada para alimentar os animais. A madeira usada na construção da viola-de-cocho é proveniente de várias espécies: para o corpo do instrumento, as preferidas são, de modo geral, as macias, mais fáceis de escavar, como a ximbuva e o sarã; para o tampo, raiz de figueira; para as demais peças, o cedro. Observa-se também 0 uso de outras espécies 
de madeira, variando de região para região, de artesão para artesão. Sobre um pedaço é desenhado o formato da viola, com base em um molde. A viola étal hada com várias ferramentas: plaina, machado, serrote, formão, martelo, estilete, trincha, lixa, motoserra, facão e pregos. 0 tampo é recortado em uma fina tábua de raiz de figueira, conforme o mesmo molde. A colagem das partes é feita, tradicionalmente, usando-se o sumo da batata conhecida como sumbaré ou, em sua falta, um grude preparado com a vesícula natatória dos peixes, uma pequena bexiga conhecida como poca. Os pontos (trastes) são confeccionados com fios de al godão, revestidos com cera de abelha.

A maioria das violas arma-se com cinco cordas singelas, quatro de tripa de animal e uma de aço. Para o preparo das cordas, é preciso limpar, esticar, e torcer as tripas do animal. Depois, para adquirir resistência, elas são curtidas em urina ou no sistema de fumeiro: durante três dias, as cordas são colocadas sobre uma fogueira de madeira verde, que produz muita fumaça; em seguida, são retiradas e esfregadas até que obtenham espessura uniforme.

A viola-de-cocho tem dois ou três pontos (trastes). Q uando são três, o intervalo entre eles é de semitom; quando são dois, o primeiro é de um tom e o segundo é de semitom. 0 instrumento tem duas afinações básicas: canotio solto e canotio preso, muito semelhantes. Os acordes usados são basicamente os de tônica e de dominante com sétima; eventualmente, armase 0 de subdominante. No siriri, em que este último acorde é mais usado, a afinação empregada é canotio preso, de forma que ele possa ser armado com apenas dois dedos. A mesma armação, contudo, é muitas vezes empregada na afinação canotio solto.

No cururu, no siriri, na dança-de-São Gonçalo e no boi-a-serra, a viola-de-cocho desempenha o papel de sustentação harmônica do canto, por meio dos acordes acima mencionados, executados de acordo com padrões rítmicos distintos que caracterizam cada um dos gêneros citados. Cururu, siriri e dança-de-São Gonçalo apresentam estilos próprios no que tange à música, à poesia e à coreografia.
A roda de cururu é constituída de momentos que apresentam uma seqüência. No primeiro deles, observamos as trovas compostas na forma versos mais toadas. Os versos e toadas são específicos e dizem respeito a cada um dos momentos da celebração. São trovas criadas pelos próprios cururueiros, pelos seus pais e avós, e giram em torno de temas como o amor, a natureza, o cotidiano, o país e a vida dos santos. A s trovas vão sendo tiradas e prosseguem com a passagem da cantoria de um para outro cururueiro, dentro do círculo formado.

A segunda corda da viola é a que serve de referência para a afinação de todas as violas presentes na roda. A altura da afinação é feita 'de ouvido', não sendo utilizado nenhum outro tipo de instrumento ou diapasão como referência sonora. A o final da cantoria de determinando cururueiro dentro da roda, é comum ocorrer uma sessão de conferência da afinação das violas, sendo rotineiro também que durante a noite a afinação vá subindo aos poucos.

Do ponto de vista rítmico, é nítida a diferença entre o cururu e o siriri. 0 ritmo do cururu é feito em compasso binário simples (2/4); 0 do siriri, em compasso binário composto (6/8), com uma variação da divisão da pulsação entre três e quatro batidas.

As rodas de cururu e siriri acontecem nas festividades locais, como dias santos, casamentos e aniversários, bem como em festas organizadas como pagamento de promessas. $N$ as festas católicas das localidades, especialmente as do ciclo joanino - São Pedro, Santo A ntônio e São J oão - , há sempre uma roda de cururu que, composta de um grupo de homens, dança em círculo e toca violas-de-cocho e ganzás (reco-recos de taquara), cantando suas louvações ao santo homenageado, cuja imagem está em um al tar. D evotos de um determinado santo - geralmente donos de uma imagem sua ou indivíduos a ele ligados por força de promessa - organizam-se em irmandades que promovem anualmente a festa e convidam um grupo de cururueiros para cantar e dançar. A o lado do ganzá e do mocho (um banco cujo assento de couro é percutido com baquetas de madeira), a viola-de-cocho forma o conjunto instrumental que acompanha a dança do siriri. Dançado principalmente por mulheres, o siriri tem lugar 
nas mesmas festas católicas ou em outras ocasiões festivas, como o carnaval. A versão mato-grossense da dança-de-São Gonçalo também tem, no acompanhamento instrumental, a viola-de-cocho. Além disso, ela pode ser tocada em bailes ou como simples passatempo.

Tanto o cururu como o siriri fazem parte do calendário anual de festividades das localidades identificadas. Normalmente os cururueiros estão ligados a um grupo ou a uma irmandade que promove as festas nos dias consagrados aos santos padroeiros, reunindo os recursos necessários. Algumas das principais festas realizadas hoje contam, também, com a ajuda e a colaboração de autoridades e pessoas ilustres. M as grande parte dos recursos é obtida junto à família do festeiro.

Os grupos de cururueiros podem ser requisitados para tocar nas festas promovidas pelas irmandades e pelos devotos da região, quando Ihes são oferecidas condução e alimentação; em alguns casos, fornece-se até mesmo o uniforme. Porém, muitas vezes não recebem nenhum tipo de remuneração, cantando e tocando por pura devoção. Tradicionalmente, no cururu não é usado nenhum tipo de uniforme, enquanto nos grupos de siriri seu uso éfreqüente. 0 siriri não tem caráter religioso, como o cururu.

Foi observado ao longo das pesquisas realizadas que os cururueiros se ressentem de não realizarem mais tantas rodas de cururu e siriri como "antigamente", as quais eram promovidas no âmbito doméstico, por devoção ou diversão, "sem tempo nem hora para acabar". A tualmente tais rodas entram em calendários oficiais dos municípios, fazendo parte de shows e festas com várias atrações. 0 tempo de apresentação do cururu e do siriri é, assim, limitado. Perdendo o tom devocional, no caso do cururu, e de brincadeira, no caso do siriri.

Por outro lado, para além do cururu e do siriri, a viola-de-cocho tem sido utilizada em outros contextos musicais, por músicos, normalmente de camadas médias, de diferentes regiões do país, que experimentam sua sonoridade em várias possibilidades.
Produção, consumo, preservação e dinâmica cultural

A produção e o consumo da musicalidade da viola-de-cocho não se confundem necessariamente com a produção e o consumo do instrumento, embora estejam intimamente imbricados.

As áreas de ocorrência da viola-de-cocho, do cururu e do siriri não são áreas isoladas. As pesquisas mostraram que o consumo da musicalidade nessas áreas está, no limite, contextual izado no universo da cultura de massa, onde há um campo de possibilidades de consumo de música potencial mente amplo, mas, na verdade, limitado e condicionado por fatores de ordem ideológica, política e comercial. A ssim, a musicalidade tradicional da viola-de-cocho continua existindo em função de escolhas feitas por apreciadores, mesmo que em menor intensidade e freqüência. Observou-se também que outras experiências musicais vão sendo feitas com 0 instrumento, ampliando seu potencial e al cance no mercado de consumo.

Diferentemente de outros instrumentos musicais de uso popular (viola caipira, violão, cavaquinho, numerosos instrumentos de percussão etc.), confeccionados tanto por artesãos tradicionais quanto por indústrias, a viola-decocho é produto exclusivamente artesanal, feito por cururueiros, seja para uso próprio, seja para atender à demanda de um pequeno mercado local, constituído também por cururueiros e mestres da dança do siriri. A ssim, os cururueiros reconhecem imediatamente o fabricante de uma viola graças a certas características que individualizam o trabalho.

A lém da produção artesanal individualizada, observou-se em Cuiabá caso de processo coletivo doméstico, não-industrial, com divisão de trabalho em uma linha de montagem que proporciona aumento de produtividade e atendimento a uma demanda maior. Existe também a produção de souvenirs e brindes para firmas e instituições diversas, para compradores de outros estados e, até mesmo, de outros países. São feitos, por exemplo, chaveiros, pequenas violas com inscrições pirografadas do tipo "Viola-de-Cocho - Cuiabá, M T", al ém de frases solicitadas pelos compradores. Os preços podem 
variar muito e dependem do comprador, já tendo alcançado R\$250. Para os cururueiros que desejam comprar uma viola, porém, os preços são mais baixos. Os artesãos de viola que não têm produção organizada reclamam da falta de mai or apoio institucional para que possam fazer dessa atividade uma profissão.

A mediação dos artesãos com o mercado mais amplo dos turistas, colecionadores e apreciadores de arte popular, fora do âmbito do cururu, é feita tanto nas casas dos próprios artesãos quanto por meio dos órgãos oficias que promovem e comercializam 0 artesanato nas Casas do A rtesão dos estados de M ato G rosso e M ato G rosso do Sul.

A o longo do mencionado projeto de apoio ao artesanato da viola-de-cocho, em Corumbá e L adário (MS), foram desenvolvidas, pelo CNFCP, oficinas de repasse de tradições, nas quais os mestres cururueiros ensinaram às novas gerações tanto as técnicas de fabricação artesanal do instrumento quanto os seus modos de execução musical. Nesse processo, foi observado um sério entrave que não se reduzia ao desinteresse dos jovens em relação ao aprendizado do modo de execução musical e de produção artesanal. $M$ as se referia à questão da relação com o patrimônio ambiental da região, posto que tradicionalmente a viola éfeita de qualidades de madeira muito específicas, cujo corte ou é proibido ou controlado. E também de elementos originais de espécies animais, como a tripa de macaco e outros bichos, que é usada para fazer as cordas; a bexiga natatória de peixes empregada para colar as partes do instrumento; a cera de abelha, para encerar os trastes...

Nesse sentido, foi necessária, junto com instituições do estado de $M$ ato $\mathrm{G}$ rosso do Sul (onde estava sendo desenvolvido o projeto de apoio ao artesanato do instrumento), a elaboração de plano de manejo ambiental para matérias-primas vegetais (madei ra) e uma substituição das matérias-primas animais por elementos industriais - como cordas de náilon, cola e cera industrial. $N$ a verdade, essas substituições já vinham sendo feitas, principalmente no $M$ ato Grosso, mas foi importante a afirmação, por parte de instituição do M inistério da Cultura, de que elas não descaracterizavam o instrumento tradicional, pelo contrário, eram necessárias para poder preservá-lo como um patrimônio nacional.

Esse fato é muito didático, pois diz sobre a diferença da preservação do patrimônio material, por meio do tombamento, e a preservação do patrimônio imaterial, por ações de salvaguarda. Podemos tombar um exemplar da viola-decocho feita tradicionalmente com matériasprimas vegetais e animais, preservando o instrumento na sua materialidade como um exemplo, em um museu. M as para preservar o instrumento como patrimônio imaterial - isto é, mantêlo permanentemente sendo produzido -, é preciso inventariar os modos tradicionais de produção e os modos alternativos e possíveis, difundindo-0s, tendo em vista a também necessária preservação do patrimônio ambiental. Pois o patrimônio imaterial deve contar com instrumentos de salvaguarda que pressuponham a dinâmica e a criatividade cultural, não "engessando" os bens. Ou seja, um dos fatores para a preservação da viola-de-cocho como patrimônio imaterial é a sua adaptação a outras matériasprimas que não as originalmente empregadas, sem, contudo, implicar sua descaracterização como instrumento musical.

A ssim, a diversificação de matérias-primas utilizadas para a fabricação da viola-de-cocho é necessária para que a preservação do patrimônio cultural não comprometa a preservação do patrimônio ambiental. E essa diversificação não descaracteriza ou ameaça a singularidade, a qualidade, o papel e o significado que esse instrumento tem na vida dos grupos de cururueiros e para 0 conjunto dos cidadãos brasileiros. A forma e a sonoridade em princípio não desaparecem; tampouco o prazer da brincadeira musical e as representações culturais associadas correm risco de extinção com a adaptação do processo de fabricação a outras matérias-primas,

A mera sustentabilidade ecológica, porém, não basta para garantir que a viola-de-cocho seja preservada do desaparecimento e do esquecimento. Não é suficiente a reprodução artesanal permanente do instrumento. É fundamental que sua musicalidade seja divulgada e legitimada pelos meios de educação, informação e entretenimento. Pois é por meio da música que a viola revela sua identidade e nos fala de 
sua cultura: um mundo povoado de jacarés, tuiuiús, homens, mulheres e santos... um universo significativo da pluralidade cultural do país.

I dentidade cultural, territorialidade e densidade histórica

Como desdobramento dos projetos de apoio ao artesanato e de inventário, em 2003 também foi real izada uma segunda exposição na Sala do A rtista Popular (a primeira foi em 1988), no Rio de aneiro (que depois seguiu para Corumbá), e foi editado um catálogo etnográfico com resultados de pesquisa desenvol vida por técnicos do projeto em Corumbá e em Ladário. Para diferenciar da exposição de 1988, o título do catálogo da exposição de 2003 foi Viola-de-cocho pantaneira e diz respeito ao nome do projeto de apoio ao artesanato desenvolvido em Corumbá e L adário, não sendo, de modo al gum, uma afirmativa de que $o$ instrumento seja originário do Pantanal.

Pelo contrário, uma leitura minimamente atenta ao texto revela que está explicitado que o pólo de referência da produção e difusão do universo cultural da viola-de-cocho está em $M$ ato Grosso, e não em M ato G rosso do Sul. E que a maioria dos cururueiros encontrados em Corumbá e L adário migrou de muitas localidades rio acima, quando os estados ainda estavam integrados.

M as é observado também que fronteiras geopolíticas não correspondem necessariamente às frontei ras culturais; e que, no caso, a recente divisão do estado de $M$ ato Grosso e a criação do estado de $M$ ato Grosso do Sul não acarretaram uma descontinuidade da cultura de tradições enraizadas muito antes do fato político. Os conhecimentos e as práticas relativas a esse universo cultural transcendem as fronteiras políticas e contêm a memória que remonta ao "estado integrado"; e isso é muito precioso do ponto de vista histórico e antropológico. A história de vida de muitos cururueiros revela a história recente dos ciclos econômicos na região, a busca de trabalho, que é também a história da devastação da natureza, dos desmatamentos nas cabeceiras do rios que provocavam enchentes que expulsavam, rio abaixo, as famílias de suas moradas...

Cultural mente, entre os cururueiros do sul e do norte, há o trânsito e o reconhecimento de referências comuns. $E$ entendemos que, se esses fatos sociais forem bem entendidos e documentados histórica e etnograficamente, no futuro (não tão distante) serão preciosidades para o conhecimento sobre os processos migratórios, de difusão cultural e dinâmica de recriação no universo relativo ao instrumento.

Essa questão é importante de ser mencionada pois suscitou protestos de cidadãos do $M$ ato G rosso que, parece, confundiram o registro do patrimônio imaterial com alguma espécie de certificado de origem do bem cultural. E pretenderam que 0 I phan retirasse a menção ao $M$ ato Grosso do Sul (Corumbá e L adário) como localidades onde a viola-de-cocho é uma referência de identidade cultural. É interessante, aqui, a problemática da disputa de um signo de identidade cultural que, do ponto de vista das evidências antropológicas, é relativo à densidade histórica de um lugar na geografia. M as, do ponto de vista dos que reivindicaram a retirada da menção à $M$ ato Grosso do Sul como região de ocorrência do bem cultural, é relativo a uma questão geopolítica.

A ssim, compreendendo, desde sempre, o fato de que o principal foco de produção e difusão da viola-de-cocho é $M$ ato $G$ rosso, mas que o bem cultural é, hoje, observado também no estado de M ato Grosso do Sul; e compreendendo também a necessidade de um reconhecimento oficial, por parte do Estado brasileiro, da importância da viola-de-cocho como um patrimônio a ser salvaguardado do desaparecimento ou da apropriação indevida (como registro de patente ou de marca), O CNFCP achou por bem aprofundar pesquisas já feitas, de modo a buscar maiores subsídios para a preparação do dossiê de instrução de registro da viola-de-cocho no L ivro dos Saberes do Patrimônio I material do I phan. Nesse sentido, em 2003 foram realizadas pesquisas em várias localidades do $M$ ato Grosso, complementando as feitas em 1988. Foram então identificadas como áreas de ocorrência do bem cultural as localidades de Cuiabá, Poconé, B arão de $\mathrm{M}$ elgaço, Jangadas, Diamantino, Nobres, Santo 
A ntônio de Leverger, Rosário Oeste, Livramento, no $M$ ato Grosso, e Corumbá e L adário, no $M$ ato $G$ rosso do Sul. Obviamente, a violade-cocho pode ser encontrada em outras localidades que escaparam ao inventário.

$D$ as pesquisas realizadas pel o CNFCP para o registro da viola-de-cocho como patrimônio nacional junto ao Iphan, resultaram, além do texto de instrução, a documentação no formato do Inventário Nacional de R eferências Culturais; um CD-ROM com edição de textos, imagens de vídeo e fotos, músicas e depoimentos; uma cartil ha de educação patrimonial , e um vídeo, todos com o objetivo de serem amplamente divulgados em território brasileiro.

$N$ esses documentos, reiteramos, $M$ ato Grosso é apontado como referência na produção e na difusão das tradições culturais relacionadas ao instrumento musical, observando-se, entretanto, a problemática mencionada acima da nãocoincidência de fronteiras geopolítcas relativamente recentes com as fronteiras culturais tradicionais, estabelecidas antes da divisão do estado do M ato Grosso e a criação do estado do $M$ ato Grosso do Sul.

0 registro e a salvaguarda da viola-decocho como patrimônio imaterial

A viola-de-cocho encontra-se em processo de transformação e observa-se que a preservação desse bem está diretamente relacionada à transmissão permanente da tradição musical: ao estímulo às novas gerações no sentido de aprender e apreciar musicalidades diversas e alternativas àquel as veiculadas pela indústria do entretenimento (o cururu e o siriri).

A lém disso, relaciona-se à transmissão permanente da tradição artesanal, e isso implica desenvolvimento continuado de planos de manejo sustentável das espécies vegetais que servem de matéria-prima e a substituição de outras matérias-primas, tendo em vista a preservação do patrimônio ambiental da região.

Nesse sentido, o Centro Nacional de Folclore e Cultura Popular desenvolveu ações com o propósito de recolher, sistematizar, proteger e salvaguardar os conhecimentos tradicionais relacionados à extração e ao uso das matériasprimas naturais (as quais estão sendo substi- tuídas pel os produtos industriais no processo de fabricação do bem) e os conhecimentos tradicionais relacionados à execução musical e aos sentidos das rodas e festas, que, na dinâmica social, vão sofrendo ressignificações ou descontextualizações, às vezes descontroladas ou desvinculadas dos interesses dos artesãos cururueiros. Com base nos conhecimentos assim acumulados, apresentou dossiê com vistas à instrução do registro da viola-de-cocho como patrimônio imaterial no Livro dos Saberes do Instituto do Patrimônio Histórico e A rtístico Nacional.

Nesse dossiê, foram identificadas duas instâncias relacionadas à preservação dos saberes relacionados à viola-de-cocho. U ma diz respeito ao interesse do público por sua musicalidade e a sua inserção no mercado de artesanato em escala que transcenda o contexto simbólico original; outra está associada à garantia das matérias-primas usadas em sua confecção.

No primeiro caso, observamos a necessidade de transmissão permanente da tradição musical. Foi identificada uma aparente contradição: os cururueiros gostam e aceitam os convites para as festas oficiais, mas reclamam que as rodas tradicionais estão perdendo espaço no âmbito da cultura de massa. Na maioria das vezes, apresentam-se no meio de outras atrações, em shows oficiais, com tempo e hora para acabar, e recebem cachês. $M$ uito diferente das rodas tradicionais, por devoção ou mera brincadeira, sem preço nem tempo marcado. A ssim, o mero apoio oficial contido no convite para as festas não é garantia de salvaguarda. Pelo contrário, pode ser um ti ro pela culatra, quando se pretende preservar a criatividade e a autodeterminação daqueles que sabem e celebram o fato cultural em questão (entende-se aqui que os maiores patrimônios imateriais a serem preservados são, no limite, a liberdade e a criatividade de um povo). 0 cultivo da roda tradicional não é, necessariamente, uma antítese da roda de show. Podem conviver com sentidos diferentes.

O segundo pressupõea transmissão permanente da tradição artesanal de maneira articulada com políticas de preservação do patrimônio ambiental. Se, por um lado, as matérias-primas 
do reino animal já são substituídas por produtos industriais, a madeira precisa ser utilizada de maneira sustentável, com base em plano de manejo e licenciamento facilitado para o corte, de maneira que 0 artesão não venha a ser um marginal em seu ofício. Pois tendo em vista a legislação ambiental que determina a autorização para o corte de árvores, muitas vezes os artesãos se vêem na posição de marginais por cortar madeira ou com el a trabal har sem esse licenciamento, dadas as dificuldades em obtê-Io junto às instituições ambientais competentes. Existem, assim, alguns obstáculos à livre produção do instrumento pelos artesãos/cururueiros que comprometem a reprodução dos saberes rel acionados à sua fabricação e à execução musical.

Entretando, apesar das ameaças de desaparecimento tanto do instrumento como de suas musical idades e cel ebrações culturais associadas, a viola-de-cocho vai sendo produzida e tocada. E reconhecida como um signo da riqueza cultural da região.

N os estados do M ato Gorsso e M ato Grosso do Sul, foi tombada como patrimônio e tem sido valorizada como um dos símbolos de identidade - Iembrança ou souvenir; objetos representativos do artesanato local.

No M ato Grosso, esse processo de tombamento foi deflagrado como reação a uma tentativa de apropriação do registro da marca "viola-de-cocho" junto ao IN PI, por um estudioso de música de Cuiabá. A pós ampla mobilização e protesto por parte dos setores ligados à cultura local, esse pedido de registro, então em caráter provisório, foi cancelado, e o bem, então, tombado.

No M ato Grosso do Sul, o tombamento veio como conseqüência de um projeto de resgate, fomento e valorização da tradição artesanal e musical que estava ameaçada de desaparecimento no estado.

0 registro da viola-de-cocho como patrimônio imaterial no Livro dos Saberes do I phan éação complementar ao esforço já empreendi do de recolher, sistematizar, proteger e salvaguardar conhecimentos tradicionais, testemunhos significativos da pluralidade cultural desta nação. 0 registro, além de ato oficial de reconhecimento e valorização dos saberes relacionados ao bem cultural, agrega valor e poderá estimular 0 desenvolvimento de políticas de preservação pelos poderes públicos, com a participação efetiva dos segmentos da população diretamente envolvidos na produção desse bem.

Desse modo, foi recomendado pelo CNFCP que as futuras ações de salvaguarda do bem em questão articulem diferentes instâncias oficiais nos âmbitos nacional, dos estadose municípios, com a comunidade, no sentido de: 1) promover o aperfeiçoamento das leis de incentivo à cultura e o desenvolvimento de instrumentos que facilitem o acesso direto dos detentores dos saberes às diferentes instâncias de patrocínio e financiamento para a produção cultural no país, de modo que tenham autonomia e agilidade; 2) estimular a interlocução entre as esferas da sociedade e os poderes públicos, para implementar um manejo ambiental continuado das matérias-primas vegetais empregadas na produção do instrumento musical (licenciamento dos artesãos para a extração controlada e progressão de replantio das espécies vegetais); 3) incentivar 0 apoio oficial às associações e aos grupos de cururueiros para que tenham condições de controlar, manter e promover a transmissão dos saberes relacionados ao bem, conforme seus interesses; 4) estimular a inclusão e 0 aprofundamento dos temas relacionados ao bem cultural na agenda escolar, de maneira que passem ao âmbito dos saberes específicos das local idades, marcas identitárias, testemunhos da riqueza cultural do país.

Esperamos que os planos de salvaguarda da viola-de-cocho sejam desenvolvidos eimplementados com intensa mobilização e articulação das comunidades locais com os poderes públicos municipais, estaduais e federal, a fim de preservar as importantes celebrações e saberes da cultura popular realcionadas a esse singular instrumento musical. Esperamos também que o caso do registro da viola-de-cocho seja uma motivação para que outras instituições e comunidades se mobilizem no sentido de desenvolver outros inventários, dossiês de registro, planos e ações de salvaguarda do patrimônio cultural brasileiro.

0 registro da viola-de-cocho não foi o único encaminhando pelo CNFCP. A té agora, no âmbito do Projeto Celebrações e Saberes da Cultura Popular, foram preparadas três candi- 
daturas: a da viola-de-cocho, a do ofício de baiana de acarajé e a do jongo. A do jongo ainda está sendo anal isada e provavel mente em breve o registro será homologado. No processo, cada caso foi único, com suas questões interessantes e relevantes, 0 que demonstra que 0 registro deve ser um instrumento flexível o bastante para as possíveis formas da imaterial idade.

No mínimo, e em geral, nos processos de construção de candidaturas para o registro do patrimônio imaterial, são produzidos conhecimentos, são articuladas várias idéias, são mobilizadas pessoas, comunidades, instituições, são alocados recursos financeiros e humanos, e formuladas ações de sal vaguarda. 0 registro em si deve ser executado como fase de processo contínuo de valorização do patrimônio cultural. É instrumento complementar e muito recente. Pode ser bem aperfeiçoado, de modo a atender às demandas sociais. $\mathrm{E}$ oxála seja eficaz!

A bstr act: Viola-de-cocho is a singular musical instnument, it is typical from Mato Grosso and Mato Grosso do Sul (Brazil). This text deals with questions relating to the recognition of this instnment as an untangible patrimony, acording to Iphan - the brazilian institution which is responsible for the preservation of the national altural patimony .

K ew-words: popular culture; brazilian patrimony; untangible patrimony .
Referências

DIAS, Letícia M artins \& VIANNA, Letícia. Violade-cocho pantaneira. Rio de

Janeiro: Funarte, CNFCP, 2003. 36 p.: il. [Sala do A rtista Popular; 109]

FONSECA, E.; TRAVASSOS, E; VIANNA, L. Violade-cocho, patrimônio nacional. In: Registro e salvaguarda para as culturas populares. Rio de Janeiro: Iphan/M inc, 2005. p. 75-89. [SérieEncontros e Estudos, 6]

TRAVA SSOS, Elizabeth; CORRÊA, R oberto. Violade-cocho. Rio de J aneiro: F unarte,

Instituto Nacional de Folclore, 1988. 22 p. il. [Sala do A rtista Popular, 43]

CD-ROM Viola-de-cocho/Patrimônio Imaterial. Projeto Cel ebrações e Saberes da Cultura Popular. Rio de J aneiro: Centro Nacional deFolcloree Cultura Popular/F unarte/M inc/2003. 